\title{
The Paradox of Facebookers in Cyber-Psychology (Religiosity, Prejudice, and Aggression)
}

\author{
F Haliq ${ }^{1}$, F Hanurawan ${ }^{2}$, M Pali $^{3}$, A Atmoko $^{4}$ \\ Social Psychology Lecturer in IAIN Madura ${ }^{1}$ \\ Social Psychology Lecturer in UM Malang ${ }^{2}$ \\ Social Psychology Lecturer in PelitaHarapan University Surabaya ${ }^{3}$ \\ Guidance and Counseling Lecturer in UM Malang ${ }^{4}$ \\ \{fathol3000@gmail.com\}
}

\begin{abstract}
Aggressive behavior does not originate from experience but various factors, including the socio-cultures, the climate of higher education institutions [1], and the swift flow of information through social media such as Facebook, Twitter, YouTube and others [2], [3]. This paper attempts to examine more deeply the aggression paradox of the Facebookerswho are involved in debates as well as its dynamics. It also sheds light on how prejudice and religiosity are triggering and controlling aggression. This paper is based on theoretical studies and researches on religiosity, prejudice, and aggression, which has been conducted from January to May 2019. This paper combines library and field researches by using a qualitative approach. The data is randomly taken from Madurese students who have Facebook and actively post comments on their own and others' pages. For the purpose of theoretical accounts, the researchers become participants by writing, commenting, and conducting conversations, debates. The dynamics of issues are ranging from the presidential and legislative elections to the politicization of certain religions and cultures.
\end{abstract}

Keyword: Religiosity, Prejudice, Aggression Paradox, Facebooker

\section{Introduction}

Aggression, as a negative behavior, finds justification in the intertwined prejudice between individuals or groups. Bullies and lies are considered true for the individual and his or her group. In this context, norms and ethics of behavior, which are central to religion and nation, are neglected to reach the goals of the moment ranging from social, cultural, and political problems. Religiosity and cultures in societies are abandoned in the name of righteousness according to the individual and his group.

In this context, the negation of the customs or the patterns of norms is driven by religiosity as part of the individuation process in which sublime norms are involved in the construction of the individual's cultures and social reality. The individuals are strengthened by the narratives that their group deliberately disseminates to reinforce behaviors that were initially hated and reprehensible as if truthfulness is found in the individual's behavior. In this case, the truth becomes limited and belongs only to the group, while other groups have the right to blame for the truthfulness of the group and itself. This is where the individual's behavior becomes counterproductive to the growing norms of society [4].

On Facebook, this behavior of aggression has escalated along with the needs for existence and the presence of vested-interest groups. Verbal aggression of hate words or speech becomes part of the daily outlook on Facebook. In 2018, Indonesia ranks the fourth Facebook users in the world, and according to We Are Social and Hootsuite, the number has reached 13 percent of a total of 3 billion users! (Kompas.com, 2/3/18). 
Figure 1.Users of Facebook in Indonesian 2018

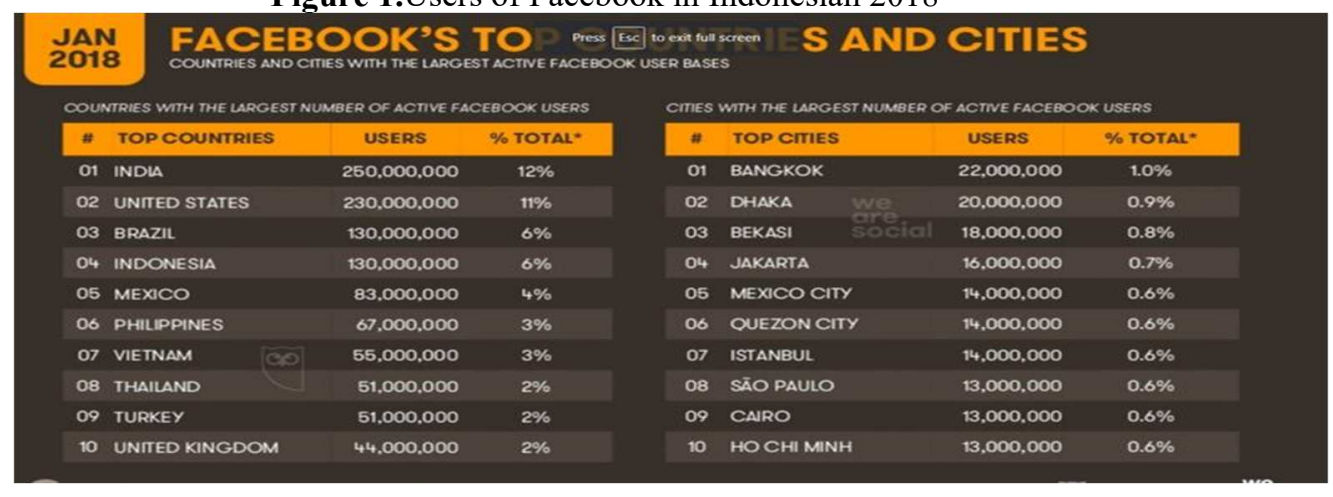

The research aims to enrich studies on aggression, especially on the paradox of aggression published first by Joireman [5], within the perspective of social psychology. Studies on aggression related to social media (sosmed) have not been much-publicized [2], although researches on social media and the user's behaviors are predicted to fill the pages of research journals. Based on the studies of concepts and theories as well as the data that the researchers collected participatory, this research will examine how aggression has its paradox; what are the scientific geneology and religiosity; who are involved in the debate and the dynamics; how prejudice and religiosity become the factors thatare triggering and controlling aggression?

\section{Method}

This research is both a library and field researches with a qualitative approach in which the researchers are participatory involved. This research started with studies on several references (books, journals, and news) related to students' religiosity, prejudice, and aggression. The next step identified and classified the university students who are active on social media, especially Facebook. The research is focused on issues related to paradoxical aggression among university students in social media.

The researchers were participatory involved in the research by writing and commenting while having conversations and debates in the dynamics of the issues related to the election of presidential candidates, the selection of candidates for legislators, and the politicization of certain religions and cultures. The data were randomly taken from Madurese students who have Facebook accounts wherein they are actively posting comments on news and status in their own pages and others. The literature and field research began in January to May 2019. The informants were Maduresestudents who are active on Facebook and whose accounts are not anonymous.

\section{Result and Discussion}

\section{The Dynamics of Facebookers in Cyber-Space}

Facebook and other social media become self-actualization for individuals. They provide a space where they wreak their thoughts, hopes, and wishes by putting words on their pages on everything they see, observe and feel in social reality. This study identified motives of activities on Facebook, which include existence (70\%), group edification (30\%), recreation (30\%), economic activity $(10 \%)$, and knowledge dissemination (10\%). Except for economic activity and knowledge dissemination, the Facebookers' motives are intertwined between existence, group edification, and recreation. This can be seen from their status and comments on several events or news and on what someone wrote on his or her page. Exchanges of response become the dynamics of their continuous engagement in one or two topics. Although in-depth research is still needed, this is one of the reasons behind the growing numbers of Facebookers in the world, in addition to the increasingly prevalent smartphone ownership 
among the young people (millennial).According to Kompas.com, the two biggest Facebook users cities in Indonesia are Bekasi (8\%) and Jakarta $(7 \%)$.

Aggression is paradoxical. It is desired by others while at the same time it makes others suffer. As a deliberate behavior, aggression is desired by the victim because it contains benefits. For example, injection or injuries that a doctor inflicted on a patient, as described in various references, is important and necessary to cure or prevent a worse thing from happening to the patient. This means that aggression is an "intentional and important" behavior because it becomes a standardized process in medicine.

However, at different times and with different intentions, aggression becomes a despicable behavior when others do not want it or feel hurt. In this case, aggression can cause disputes, conflicts, and even killings. It is quite often that Facebookers use and make justification for what they uploaded on their Facebook pages. They also sought legalization for what they have done by providing a reasonable answer that what they uploaded is true.

Facebookers who are involved in the paradox of aggression have an interesting scientific genealogy and religiosity. The data showed that scientific and religious literacy belongs to the Facebookers who have the ability and skills to write and debate within a long duration of time by producing and reproducing discourse to strengthen their personal and group interests. The irony is that weak references are sometimes made to make their debates and writings repeated. This is in contradiction with the scientific background of the informants who are relatively better than others are.

It could be said this is part of their search for recognition and existence. They actually do not care about what they (Facebookers) are arguing about because they are more interested to take a distance from others or to make a social attribution between the individuals in which identification of the group is strengthened. They make a demarcation between "our group" and "your group". This group identification is intended to reinforce justification and legality of what they write on others' Facebook pages. As they are discrediting the existence of others, the Facebookersignore the norms and rules when interpreting and responding to what other people said.

At the same time, religiosity as a controller of aggressive behavior [6] becomes neglected or absurd and it requires new interpretations from the Facebookers. In this case, religiosity is not only taken as a barometer of the individual's behavior but most importantly, it should be reformulated. This, of course, relates to the norms or values adopted by Facebookers who are different from most people in the real world. The virtual world has a more absurd norm consisting of excessive suspicion and prejudice. Regardless of social identity and structure in society, most of them adhere to the agreed norms that are in line with the interests and the tastes of the Facebookers. They adopt the same norms and the same interests at once. They will do anything to justify what they or others have done (both in a sentence and in behaviors) according to their group interests. This is where the factors are interconnected and interrelated with various variables between prejudice, religiosity, and aggression at the same time.

\section{The Aggression Paradox of the Facebookers}

The existence of aggression, on the other hand, serves as a response that provides a detrimental/damaging stimulus to the organism [7]. Aggression is a tendency or a negative behavior between the individuals in which they are sending a stimulus harmful to others ranging from pushing, hitting to killing, said Peterson [8]. Therefore, aggression is a tendency or behavior that is physically and psychologically detrimental to others. It includes hostility aggression, physical aggression, verbal aggression and angry aggression [9]. This aggression certainly benefits the aggressor but makes the victims suffer. Ironically, this behavior receives justification and legitimacy from the groups that are not on Facebook, for example.

Facebook users are mostly anonymous. In social psychology, anonymity will lead to deindividuation, a behavioral symptom to "follow the direction and behavior of the group" [10], [11]. Being anonymous means to not have a good identity, and on Facebook, it is a deliberate tendency to create prejudice between the individuals or the groups. It is important to remember that anonymous identities contain interests, direction, and orientation. An interesting thing from this research is that 
the Facebookersbeing studied are those with clear accounts that provide information on names and educational backgrounds.

In social psychology, the complexity of this aggression contains a paradox and a cultural bias [5], but it, nevertheless, often found justification [12] by which "aggression more productively" is explored and produced [4] both by the individuals and by the groups [12]. At this level, the trend or behavior of the Facebookers, as identified by Bond and Ramirez, represents the power of Facebook that always"greet the user" and the realities of the virtual world that obtain justification and legitimacy from the individuals or the groups outside. For those who are without moral-ethical powers, they will be tossed into "virtual-trusts" that easily lead to the paradoxical behaviour of aggression.

Paradoxical aggression is also happening to the students outside Facebook. In other cultures, aggressive actions committed by the individuals or the groups found their moral approval. This behavior occurs in some countries with different religious and cultural backgrounds. Lagerspetz and Westman's research on students in Finland, Poland, Spain, Japan, Iran, and India showed the level of justification for aggressive action with quality and intensity. Almost in all countries, violent forms of aggression (murder, torture) are less acceptable than any form of harmless behavior. On the same side, aggressive action can be socially justified especially for the protection of oneself or others [12].

Theoretically, aggression as behavior is triggered by the environment, while the individual reacts to the environment by acting aggressively [13]. There is physical and verbal aggression for a person [5] that can be controlled when the person acts or controls an aggressive behavior [14]. In adults, the behavior of aggression can be studied more deeply from the environment of higher education institutions (campus) and the dysfunctional family structure [15]. This can be affirmed that the behavior of aggression is not only related to personal problems, but also to a specific environment and culture.

Other analyses may use the perspective of Bronfenbrenner who develops a heuristic model of violence occurring at an educational institution. This model takes into account the interplay between individual and environmental factors and subsystems. Goldstein (1994) describes this type of layered ecological theory as an interactionist model. This theory considers human behavior as a "duet" between the personal traits and the contextual and environmental variables (social and physical). These environments may include other human beings(such as other students and teachers), physical environments (such as higher education institutions), and class sizes as well. Higher educational institutions are associated with the effects of several subsystems, such as student families, communities, and a greater social context. The heuristic theoretical model puts the context of a higher education institution at the center. This model serves as a roadmap for the conceptualization of ideas and analysis of violent aggression. In this case, empirical studies are conducted to explore the intersection between the context and the violence in higher education institutions.

Education is an important institution that provides a better alternative in interpersonal relationships. It plays an important role in changing or taking a social intervention in the learning process in order to produce students who are sensitive, emphatic, cooperative, self-controlled, prosocial, and lack of aggressive behavior and conflicts [16]. With an increase in the level of education, it is hoped that human beings can have a harmonious relationship with one another [17]. Education becomes a major provision in social relations. However, it does not mean that education is the most important thing in the social relation process, especially between the students, students, and teachers, or between the teachers [18]. Individuals are of high importance in managing their personal and social skills, knowledge, and behaviors in their daily lives.

Some studies showed the red lines between eligibility, prejudice, conflicts, and aggression among individuals in daily life. Firstly, conflict and aggression are interesting when associated with religiosity. Some of the aforementioned cases suggested that the characteristics of a religious person become absurd or blurred when linked to behaviors of conflict and aggression. During the month of Ramadhan, for example, conflict and aggression are subsided but escalated after. Conflict and aggression have a positive relationship with a person's religiosity. Secondly, the individual and the environment become a unique and interesting part that need to observe for the two are always flashing in all the events mentioned earlier. The individual and the environment become an inseparable part of earlier studies on conflict events and aggression. Interpersonal conflicts, as Joiremen said [5] are part of the past events related to personality and conditions or situations surrounding them or to the number of persons involved. This study found that the more often parents are in a quarrel with the 
respondent the more often they, whether the father or his mother, would beat their children. This suggests that aggressive parents transmit an aggressive view of their children.

On the other hand, religiosity in the sense of religious practices gives stimuli to behavior through established values in a particular culture [19], [20]. Watkins' research [21] found that religious familiarity and aggression provide an important insight into why individuals may or may not act aggressively. The research of McCullough [22] also explained that there are many religious values related to health, wellbeing, and social behavior. In this case, religiosity is part of the control over the behavior of aggression [23]. Behavioral modification can occur when there are values that affect such religious values, which in the context of this research is related to the learning process in the environment. Allport proposed the idea of a paradox in religion. Allport explained that the irony of life lies in the paradox of religious behavior, "it is prejudiced and it does not prejudice." All religions teach universal tolerance and compassion but religious practices often encourage intolerance and hatred [24].

Aggression is not the only individual but also cultural. Kontowijoyo found that in Mature there is a culture within a small family scope called Tanean-Lanjhang [25]. This behavior is also part of the stigma that appears for some people who do not know the Madurese who have developed since the colonial era (Jonge, 1994). The stigma is culturally transmitted to raise the dignity of the other groups (Jonge, 2004).

Education also shaped the individual characteristics, including the Madurese. The education that is rooted in moral behavior refers to the obedience to certain cultures and ethics. For the Madurese, chastity is important and is rooted in religious education. Kuntowijoyo recorded that the Madurese have strong traditions beginning before the colonial era [25]. The individuals hold firmly their cultures imbued with religious values. "Carol" becomes another part that cannot be separated from the individuals in Madura.

\section{Conclusion}

Aggression can be said is part of the Facebookers' search for recognition and existence. They actually do not care about what they (Facebookers) are arguing about because they are more interested to take a distance from others or to make a social attribution between the individuals in which identification of the group is strengthened. They make a demarcation between "our group" and "your group". This group identification is intended to reinforce justification and legality of what they write on others' Facebook pages. As they are discrediting the existence of others, the Facebookersignore the norms and rules when interpreting and responding to what other people said.

Religiosity is a controller of aggressive behavior [6] but it becomes neglected or absurd among the Facebookers. This relates to the norms or values adopted by Facebookers who are different from most people in the real world. The virtual world has a more absurd norm consisting of excessive suspicion and prejudice. Regardless of social identity and structure in society, most of them adhere to the agreed norms that are in line with the interests and the tastes of the Facebookers. They adopt the same norms and the same interests at once. They will do anything to justify what they or others have done (both in a sentence and in behaviors) according to their group interests. This is where the factors are interconnected and interrelated with various variables between prejudice, religiosity, and aggression at the same time.

\section{Reference}

[1] F. A. Sava, "Causes and effects of teacher conflict-inducing attitudes towards pupils: A path analysis model," Teach. Teach. Educ., vol. 18, no. 8, pp. 1007-1021, 2002.

[2] M. Appel, "Internet Use and Verbal Aggression: The Moderating Role of Parents and Peers," Comput. Human Behav., vol. 33, pp. 1-32, 2014.

[3] D. Upton et al., "Computers in Human Behavior Social media as a vector for youth violence : A review of the literature COMPUTERS IN HUMAN BEHAVIOR." 2014, doi: 
[4] M. H. Bond, "Culture and Aggression-From Context to Coercion," Personal. Soc. Psychol. Rev., vol. 8, pp. 62-74, 2004, doi: https://doi.org/10.1207/S15327957PSPR0801.

[5] J. Joireman, J. Anderson, and A. Strathman, "The Aggression Paradox: Understanding Links Among Aggression, Sensation Seeking, and Consideration of future Consequences," J. Pers. Soc. Psychol., vol. 84, no. 6, pp. 1287-1302, 2003, doi: https://doi.org/10.1037/00223514.84.6.1287.

[6] N. N. Sydney-agbor, "Impact of Religiousity, Family Relations and Gender on Aggressive Behaviours among Undergraguates," . Int. J. Soc. Sci. Humanit., vol. 6, no. 1, pp. 42-46, 2016, doi: https://doi.org/10.7763/IJSSH.2016.V6.615.

[7] F. Hanurawan, Psikologi Sosial. Malang: FIP Universitas Negeri Malang, 2011.

[8] L. Berkowitz, Aggression: Its Causes, Consequences and Control. New York: McGraww Hill, 1993.

[9] M. Buss, A. H., \& Perry, "The Aggression Questionnaire," J. Pers. Soc. Psychol., vol. 63, no. 3, pp. 452-459, 1992, doi: https://doi.org/10.1037/0022-3514.63.3.452.

[10] F. Johnson, JW; Johnson, Joining Together: Group Theory \& Group Skill. Boston: Allyn \& Bacon, 2000.

[11] S. H. Vilanova, F., Beria, F. M., Costa, Â. B., \& Koller, "Deindividuation: From Le Bon to the social identity model of deindividuation effects," Cogent Psychol., vol. 4, no. 1, pp. 1-21, 2017.

[12] J. M. Ramirez, J. M. Andreu, T. Fujihara, Z. Musazadeh, and S. Saini, "Stification of aggression in several Asian and European countries with different religious and cultural background," Int. J. Behav. Dev., vol. 31, no. 1, p. 9, 2007.

[13] C. N. DeWall, E. J. Finkel, and T. F. Denson, "Self-control inhibits aggression," Soc. Personal. Psychol. Compass, vol. 5, no. 7, pp. 458-472, 2011, doi: https://doi.org/10.1111/j.1751-9004.2011.00363.x.

[14] C. N. DeWall, R. F. Baumeister, T. F. Stillman, M. T. Gailliot, C. R. McAdams III, and V. a. Foster, "Violence restrained: Effects of self-regulation and its depletion on aggression," $J$. Exp. Soc. Psychol., vol. 43, no. 1, pp. 62-76, 2007.

[15] V. a McAdams III, C. R., \& Foster, "Dysfunctional Family Structure and Aggression in Children: A Case for School-Based, Systemic Approaches with Violent Student," Coll. William Mary, pp. 1-33, 2009.

[16] D. R. Shaffer, Social and Personality Development. USA: Thomson Wadsworth, 2005.

[17] R. Shah and M. Lopes Cardozo, Educational Psychology: Theory and Practice. 2014.

[18] R. Maulana, R., Opdenakker, M. C., den Brok, P., \& Bosker, "Teacher-student interpersonal relationships in Indonesia: Profiles and importance to student motivation," Asia Pacific J. Educ., vol. 31, no. 1, pp. 33-49, 2011, doi: https://doi.org/10.1080/02188791.2.

[19] P. Van Coppellen and V. T.-G. Saroglou, "Religiosity and Prosocial behavior and Churchgoers: Explorng Undrlying Mechanisme," vol. 2, no. 2337, pp. 1-2, 2014.

[20] V. Saroglou, V. Delpierre, and R. Dernelle, "Religiosity: A meta-analysis of studies using Schwartz's model," Pers. Individ. Dif., vol. 37, no. 4, pp. 721-734, 2004, doi: https://doi.org/10.1016/j.paid.2003.10.005.

[21] S. J. Watkins, "Religiosity and aggression in college students. ProQuest Dissertations and Theses." pp. 72-72, 2003, doi:

http://ezproxy.net.ucf.edu/login?url=http://search.proquest.com/docview/250229938?accounti $\mathrm{d}=10003 \% 5 \mathrm{Cnhttp} / / / \mathrm{sfx}$. fcla.edu/ucf?

[22] B. L. B. McCullough, M. E., \& Willoughby, "Religion, Self-Regulation, and Self-Control: Associations, Explanations, and Implications," Psychol. Bull., vol. 135, no. 1, pp. 69-93, 2009, doi: https://doi.org/10.1037/a0014213.

[23] P. Kumar, "Religious Attitude, Modernization and Aggression of College Going Students and Its Impact on Their Academic Achievement," Int. J. Educ. Psychol. Res., vol. 3, no. 2, pp. 3945, 2014.

[24] E. al Davidio, John F., On Nature of Prejudice. Australia: Blackwell Publishing, 2005.

[25] Kuntowijoyo, Perubahan Sosial Dalam Masyarakat Agraris Madura 1850-1940. Jogjakarta: Mata Bangsa, 2002. 
